\title{
Pure Mucinous Breast Carcinoma Mimicking a Benign Phyllode Tumor: Case Report and Review of Literature
}

\author{
H Asmouki ${ }^{1,3}$, J Ouchraa ${ }^{1,3^{*}}$, M Kabine ${ }^{1,3}$, K Harou $^{1,3}$, H Rais ${ }^{2,3}$, A. Soummani ${ }^{1,3}$ \\ ${ }^{1}$ Department of Obstetrics \& Gynecology, University Hospital Mohammed VI Marrakech, Morocco \\ ${ }^{2}$ Department of Anatomic Pathology, University Hospital Mohammed VI, Marrakech, Morocco \\ ${ }^{3}$ Cadi Ayyad University, Marrakech, Morocco
}

DOI: $10.36348 /$ sijog.2020.v03i02.005

| Received: 06.02.2020 | Accepted: 13.02.2020 | Published: 16.02 .2020

*Corresponding author: Ouchraa Jihane

\section{Abstract}

Pure mucinous breast carcinoma is a very rare histopathological type of breast cancer. Despite its invasive nature, mucinous carcinoma is most often described as a benign lump. It can be misdiagnosed as a phyllode tumor, which has certain similarities both clinically and radiologically. Surgery is the cornerstone of therapeutic management: lumpectomy or mastectomy depending on the size of the tumor, associated with axillary lymph node dissection or with sentinel lymph node biopsy procedure for early stage tumors. The treatment is often associated with adjuvant chemotherapy and radiotherapy. We describe an uncommon case of pure mucinous breast carcinoma, which clinical and radiological characteristics, occurred as a benign phyllode tumor presenting a real diagnostic challenge.

Keywords: Pure mucinous carcinoma, phyllode tumor, breast cancer.

Copyright @ 2020: This is an open-access article distributed under the terms of the Creative Commons Attribution license which permits unrestricted use, distribution, and reproduction in any medium for non-commercial use (NonCommercial, or CC-BY-NC) provided the original author and source are credited.

\section{INTRODUCTION}

Mucinous carcinoma of the breast was first described in 1826 by the World Health Organization (WHO), defining it by the presence of malignant mucosecreting tumor cells floating in mucin [1]. Also called colloid or gelatinous or mucoid carcinoma, it constitutes a rare histological type of breast neoplasms, representing 1 to $4 \%$ of all breast cancers. The pure mucinous breast carcinoma subtype is extremely rare and account for about $2 \%$ of all primary breast carcinomas [2]. We report an original case of pure mucinous breast carcinoma, discovered in a 70-year-old patient with a large breast lump, which clinically and radiologically appeared as a phyllode tumor causing diagnostic difficulties. The diagnosis of mucinous breast carcinoma was only confirmed by histopathological examination.

\section{CASE REPORT}

A 70 years old, single lady, nulligravida, menopaused for 20 years, with no personal or family history of breast cancer, who had noticed a painless lump in the right breast, discovered on selfexamination, and was gradually enlarging.
Clinical breast examination revealed a smooth, well defined, firm, retro-areolar mass of $10 \times 8 \mathrm{~cm}$, nonfixed to the neither superficial nor deep tissue plane, with no inflammatory features or nipple discharge. The axillary hollow was free.

Mammography and ultrasonography showed two opacities with well circumscribed margins in the right breast, and no micro-calcifications. One was retroareolar, with multi lobulated borders, that measures $7 \mathrm{~cm}$, the second was located at the upper inner quadrant measuring $06 \times 3,5 \mathrm{~cm}$. No significant axillary lymphadenopathy was demonstrated either clinically or radiologically. The benign radiological appearance would favor the diagnosis of two phyllod tumors (Fig1). A surgical biopsy was performed, revealing a mucocele-like lesion versus a mucinous carcinoma (Fig-2). Immunohistochemistry identified a specific subtype of pure mucinous carcinoma grade II SBR and showed estrogen and progesterone receptor positivity (ER \& PR), receptor (Her 2) negative and Ki-67 (+) on $10 \%$ of tumor cells. The initial extension assessment was negative. A mastectomy with lymph node 
H Asmouki et al; Sch Int J Obstet Gynec, Feb. 2020; 3(2): 40-43

dissection was performed to complete the surgical treatment. The final histological study identified a pure mucinous carcinoma, $16 \mathrm{~N}-/ 16 \mathrm{~N}$, pT3N0Mx; the patient received also an adjuvant chemotherapy. The evolution after 6 months was favourable, the extension assessment remains negative.
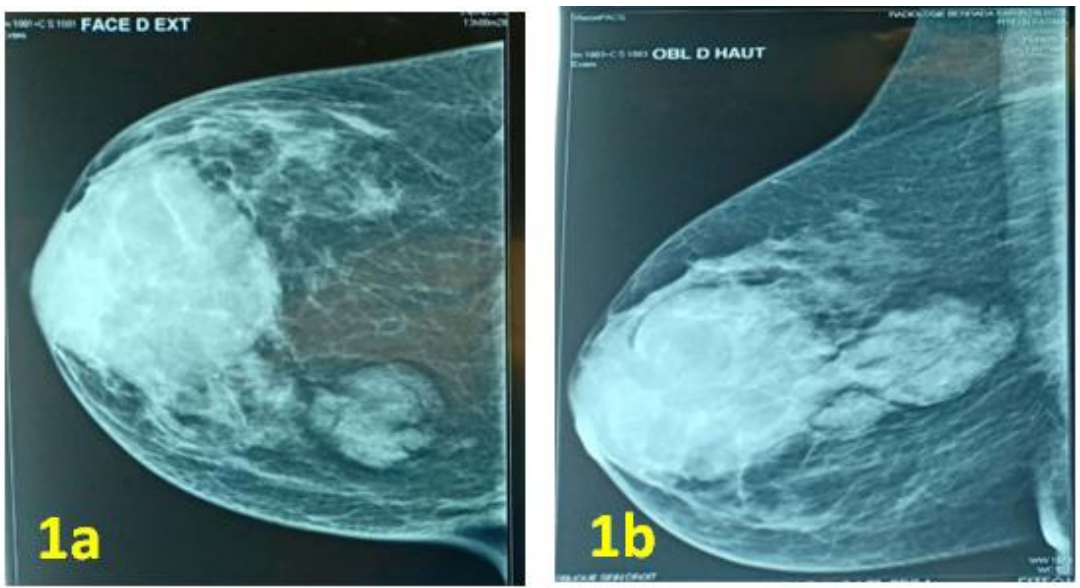

Fig-1: Mammography of the right breast showing two well circumscribed opacities with no microcalcifications (Fig 1a= frontal incidence; Fig $\mathbf{1 b}=$ oblique incidence)
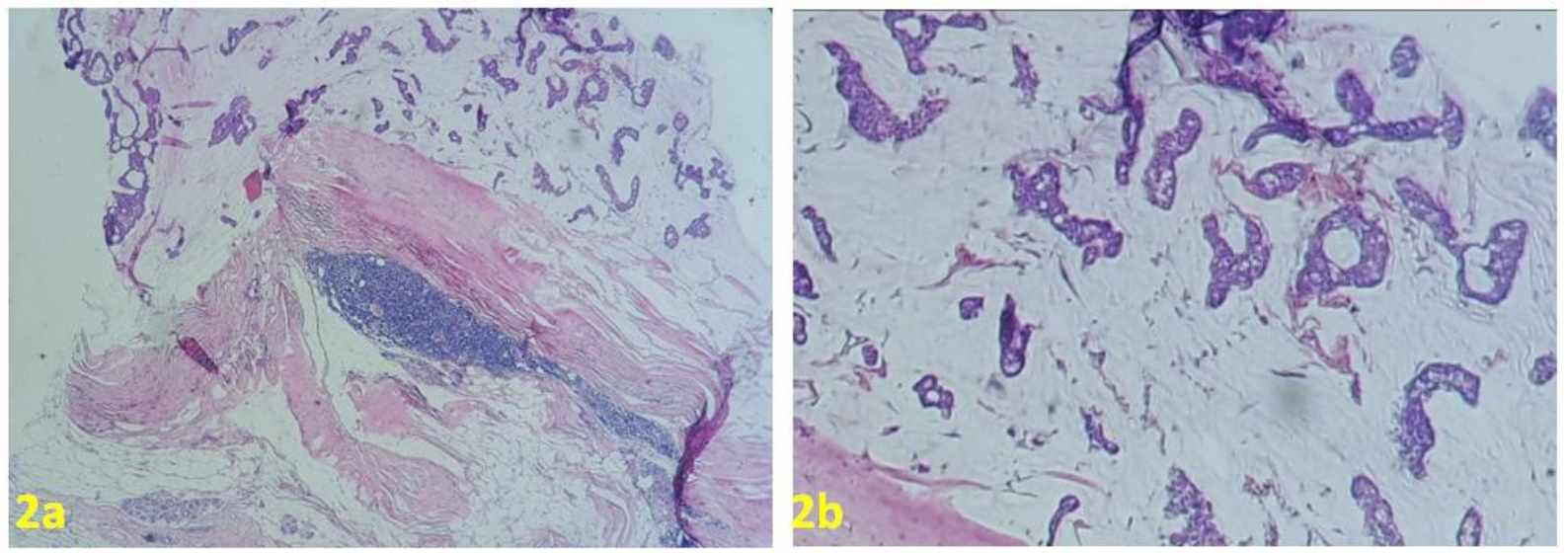

Fig-2: Histological features of mucinous breast carcinoma showing breast parenchyma site of an invasive carcinomatous proliferation (Fig $2 \mathrm{a}=$ microscopic magnification $x 4$; Fig $2 b=$ microscopic magnification $x 20$
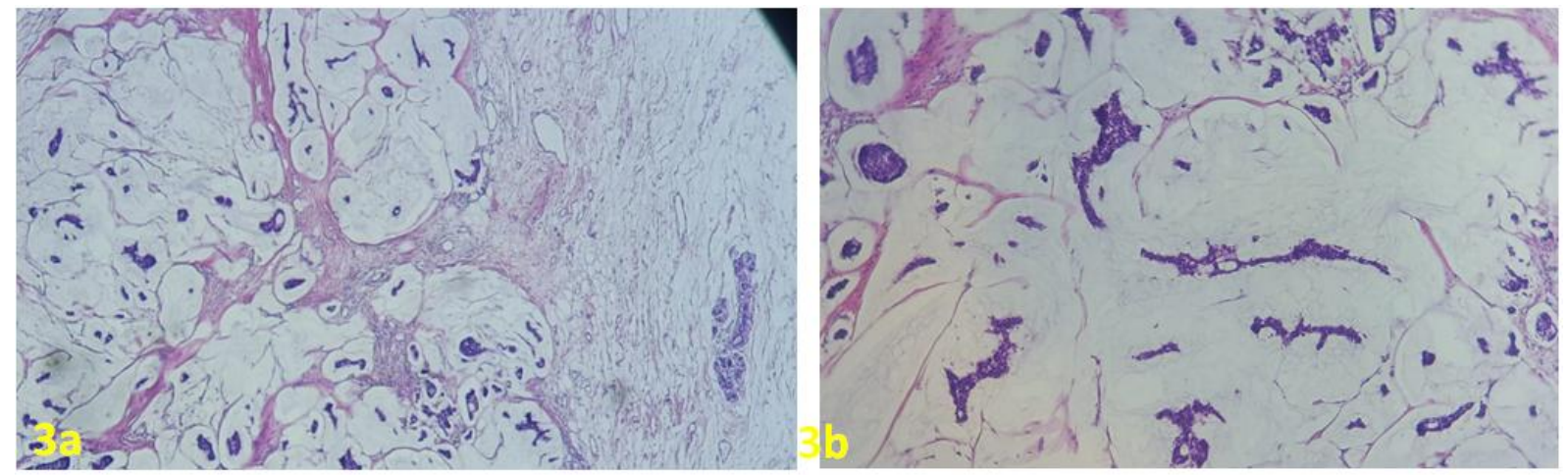

Fig-3: Light microscopy (x4 Fig 3a \& x20 Fig 3b) demonstrates proliferation made of large pools of mucus occupying $>90 \%$ of the tumor, glands and clusters of tumor cells of varying sizes

\section{DISCUSSION}

Mucinous carcinoma of the breast is a rare histological entity which preferentially affects women over sixty years. Its prevalence is $3 \%[3,5]$. This carcinoma is revealed in $80 \%$ of cases by auto palpation of a well-defined lump, classified T1 or T2 according to the classification Tumor Node Metastasis (TNM) $[4,5]$ with extremes of 0.3 and $19 \mathrm{~cm}$ reported from the literature [6]. Axillary lymphadenopathy is rarely found $(<25 \%$ of cases) [6, 7]. Barkley and DiSaverio have shown a correlation between tumor size and lymph node metastases. Indeed, the presence of a lymph node is associated with a larger tumor size $[1,8]$. Nevertheless, we noticed in our patient, the absence of 
lymph node invasion despite the large size of the tumor which reached $10 \mathrm{~cm}$, orienting more towards a benign tumor.

According to Tan, Bode and Memis [9-11], pure mucinous carcinoma appears on mammography as a well circumscribed opacity similar to the aspect of a phyllode tumor, with regular contours, rarely associated with micro calcifications [12]. Falsely reassuring, the ultrasound complement shows in $71 \%$ of the cases posterior acoustic enhancement explained by the presence of cystic component in the pure type of mucinous carcinoma [11]; leading to misdiagnosis as a phyllode tumor or a reshaped cysts as it was for our patient. Therefore, the presence of a posterior enhancement should not lead to a wrong conclusion of a reshaped cyst, or a benign tumor. The mixed type of mucinous carcinoma appears as hypoechoic masse with spiculated margins and a higher frequency of intra or peri-tumor calcifications, showing the aggressiveness of this subtype. Tumor vascularization can also be found in one third of the mucinous carcinomas [13].The bilateral character is rarely described, while multifocality remains exceptional [7]. Our patient had the particularity of having a bifocal aspect of the tumor revealed on ultrasound.

MRI has higher sensitivity for detection of mucinous carcinomas, the main characteristic is a homogeneous hyperintense signal on T2 [10-12]. This is probably due to the specificity of the mucinous component. The diversity of the imaging findings calls for caution. No radiological criteria seem to allow an etiological diagnosis. Therefore, the diagnosis of mucinous carcinoma is considered as an imaging challenge.

Histologically, mucinous carcinoma is built up of rich extracellular mucin in which a cluster of tumor cells float as separate groups. It may occur in two forms [14]: the pure form in which all the tumor cells, even at the invasive margins, are surrounded by extracellular mucin constituting a real mechanical barrier attenuating cellular invasion. The fibrous reaction is weak or absent and the transition between mucus and surrounding connective tissue is abrupt.

The mixed form contains invasive areas not surrounded by mucin, often identical to the usual type of invasive ductal carcinoma or some of the special histologic types. The fibrous reaction is predominant and the transition between extracellular mucus and adjacent carcinomatous tissue is gradual. Most pathologists agree that a diagnosis of pure mucinous breast carcinoma should be reserved for tumors with at least $90 \%$ mucinous component [7]. The pure subtype is often well-differentiated with positive hormone receptors and human epidermal growth factor receptor (HER-2) negative.
The distinction between both subtypes is crucial due to its prognostic value. Neuroendocrine differentiation gives a favourable prognosis to mucinous carcinoma, in particular a lower nuclear grade, a greater expression of oestrogen receptors $(91 \%$ of cases) [11] and a low incidence of lymph node metastases. In our case, it was the histological examination of the lumpectomy that confirmed the diagnosis, objectifying a mammary carcinoma of specific type: pure mucinous subtype SBR II, HER2negative.

Studies show that HER2 status is an independent prognostic indicator of overall survival in pure mucinous breast carcinoma (PMBC). Given the unfavourable prognosis and aggressive clinical features of HER2-positive PMBCs, the determination of HER2 status in PMBC should warrant special attention [15, $16]$

The therapeutic management is surgical [7] by lumpectomy or mastectomy depending on the size of the lump associated to an axillary lymph node dissection or a sentinel lymph node biopsy. Breastconserving therapy must be carcinological and aesthetic in view of the favourable prognosis. As for the other therapeutic pillars, namely chemotherapy, radiotherapy and endocrine therapy, their indications are similar to those of other breast carcinomas [5, 6].

During the first assessment of extension, the discovery of metastatic locations is rare [8]. Several authors have agreed that lymph node status is the main significant prognostic factor, followed by age, size, hormonal and HER2 status $[1,2]$. The low incidence of lymph node metastases in the pure forms of colloid carcinoma ( 2 to $14 \%$ compared to 45 to $64 \%$ in mixed forms) explains the favorable prognosis of the latter [5, 6], with 90 to $100 \%$ survival in ten years against $60 \%$ in mixed forms [17].

\section{CONCLUSION}

Pure Mucinous carcinoma of the breast is a rare variety, occurring mainly in elderly postmenopausal women. Its clinical and radiological diagnosis can be confused with benign tumors, as the phyllode tumor. Caution is advised and histological proof is essential before any therapeutic treatment.

\section{REFERENCES}

1. Di Saverio, S., Gutierrez, J., \& Avisar, E. (2008). A retrospective review with long term follow up of 11,400 cases of pure mucinous breast carcinoma. Breast cancer research and treatment, 111(3), 541-547.

2. Naqos, N., Naim, A., Jouhadi, H., Taleb, A., Bouchbika, Z., Benchakroune (2016). Mucinous carcinoma of the breast: Clinical biological and 
H Asmouki et al; Sch Int J Obstet Gynec, Feb. 2020; 3(2): 40-43

evolutive profile [Carcinome mucineux du sein: profil clinique biologique et évolutif].

3. Mayi-Tsonga, S., Meye, J. F., Pither, S., \& Nguizi, S. (2004). Carcinome mucineux du sein et fibroadénomes récidivants: difficultés diagnostiques à propos d'une forme clinique bilatérale: Mucinous breast carcinoma and recurrent fibroadenomas: diagnosis difficulties about a bilateral clinical form. Imagerie de la Femme, 14(1), 23-26.

4. Georges, A., Lacroix, J., \& Boute, V. (2016). Mucinous carcinoma: A rare malignant breast tumour. Imagerie De La Femme, 26(1), 8-20.

5. Komenaka, I. K., El-Tamer, M. B., Troxel, A., Hamele-Bena, D., Joseph, K. A., Horowitz, E., ... \& Schnabel, F. R. (2004). Pure mucinous carcinoma of the breast. The American journal of surgery, 187(4), 528-532.

6. Ishikawa, T., Hamaguchi, Y., Ichikawa, Y., Shimura, M., Kawano, N., Nakatani, Y., ... \& Shimada, H. (2002). Locally advanced mucinous carcinoma of the breast with sudden growth acceleration: a case report. Japanese journal of clinical oncology, 32(2), 64-67.

7. Dumitru, A., Procop, A., Iliesiu, A., Tampa, M., Mitrache, L., Costache, M., ... \& Cirstoiu, M. (2015). Mucinous breast cancer: a review study of 5 year experience from a hospital-based series of cases. Maedica, 10(1), 14.

8. Barkley, C. R., Ligibel, J. A., Wong, J. S., Lipsitz, S., Smith, B. L., \& Golshan, M. (2008). Mucinous breast carcinoma: a large contemporary series. The American journal of surgery, 196(4), 549-551.

9. Bode, M. K., \& Rissanen, T. (2011). Imaging findings and accuracy of core needle biopsy in mucinous carcinoma of the breast. Acta Radiologica, 52(2), 128-133.

10. Tan, J. Z. Y., Waugh, J., Kumar, B., \& Evans, J. (2013). Mucinous carcinomas of the breast: imaging features and potential for misdiagnosis. Journal of medical imaging and radiation oncology, 57(1), 25-31.

11. Memis, A., Ozdemir, N., Parildar, M., Ustun, E. E., \& Erhan, Y. (2000). Mucinous (colloid) breast cancer: mammographic and US features with histologic correlation. European journal of radiology, 35(1), 39-43.

12. Liu, H., Tan, H., Cheng, Y., Zhang, X., Gu, Y., \& Peng, W. (2011). Imaging findings in mucinous breast carcinoma and correlating factors. European journal of radiology, 80(3), 706-712.

13. Lam, W. W. M., Chu, W. C. W., Tse, G. M., \& Ma, T. K. (2004). Sonographic appearance of mucinous carcinoma of the breast. American Journal of Roentgenology, 182(4), 1069-1074.

14. Anan, K., Mitsuyama, S., Tamae, K., Nishihara, K., Iwashita, T., Abe, Y., ... \& Toyoshima, S. (2001). Pathological features of mucinous carcinoma of the breast are favourable for breastconserving therapy. European Journal of Surgical Oncology (EJSO), 27(5), 459-463.

15. Jang, Y., Jung, H., Kim, H. N., Seo, Y., Alsharif, E., Nam, S. J., ... \& Cho, S. Y. (2019). Clinicopathologic characteristics of HER2positive pure mucinous carcinoma of the breast. The Korean Journal of Pathology.

16. Wei, Y. N., Liu, S., Zhang, M. L., Ke, X. X., Chen, M., \& Wei, B. (2019). Clinicopathologic characteristics of HER2-positive pure mucinous breast carcinoma: a systematic investigation into an unusual tumor. International Journal of Clinical and Experimental Pathology, 12(5), 1666.

17. Paramo, J. C., Wilson, C., Velarde, D., Giraldo, J., Poppiti, R. J., \& Mesko, T. W. (2002). Pure mucinous carcinoma of the breast: is axillary staging necessary?.Annals of surgical oncology, 9(2), 161-164. 